\title{
Disaggregated Analysis of Performances of Grade 12 Learners in Gauteng Province, Republic of South
} Africa

\author{
Letsoalo ME \\ Directorate of Research and Innovation \\ Tshwane University of Technology, Pretoria, South Africa \\ MaupiELetsoalo@gmail.com, LetsoaloME@tut.ac.za
}

\begin{abstract}
This paper presents the researchers' interpretive analysis of data from the main study that was aimed at proposing the method that will plausibly be used to analyse the Grade 12 results and to compare performances of learners between provinces of South Africa. This cross-sectional, quantitative, and ex-postfacto designed study used secondary and clustered data, as supplied by Department of Basic Education through Umalusi council, to compare the likelihood of passing Grade 12 between male and female learners in the Gauteng Province, even after adjusting for school quintile. Thus, this work attempted to model the relation between school resources inputs and school outcomes called educational achievements or academic performances. The dataset contained a total of 98894 (45.44\% male and 54.56\% female) learners who set for Grade 12 examinations in 2008 academic. The crude estimates indicated that female learners than male learners were significantly 1.035 more likely to pass Grade 12 (OR $=1.035, \mathrm{p}=0.016,95 \% \mathrm{CI}$ : $1.006-1.065$ ). Also, the school quintile adjusted model indicated that female learners than their male counterparts were significantly 1.040 more likely to pass Grade 12 (OR = 1.040, $\mathrm{p}=0.010,95 \% \mathrm{CI}: 1.009-1.072$ ). The significant effect of school quintile favoured female learners $(p<0.001)$. These results, from disaggregated analysis, indicated that there was sufficient evidence that female than male learners had better chances of passing Grade 12 in Gauteng Province. Therefore, authorities may consider the issue of learner-gender when allocating resources to different school In Gauteng Province.
\end{abstract}

\section{Keywords: Academic performance, disaggregated analysis, Grade 12, odds ratio, school quintile}

\section{Introduction}

Academic performances of learners, described as the scholastic standing of a learner at a given moment (Adeyemi, 2008) - referring to how an individual is able to demonstrate his or her intellectual abilities, come from cognitive and non-cognitive factors. Cognitive factors are memory, verbal abilities and aptitudes for reasoning; and these can be measured using performance and achievement tasks, where the answer given can be grouped as correct or incorrect, or acceptable and not acceptable. For decades and even now a lot of non-cognitive factors have affected performance (Dee, 2005; Kyei \& Maboko, 2016). In other words, as highlighted by Fan and Chen (Fan \& Chen, 2001), the educating community's focus is now on non-cognitive factors because the realisation of these factors is evidenced. Studies have been conducted to determine factors that have effect on learners' academic performances. Rich (2000) found that family structure has a significant effect on learner performance. In particular, the findings by Rich (2000) indicated that learners from single-headed families or sole parent families performed significantly lower. Lacour and Tissington (2011) reported that poverty significantly affect learners' academic achievement; for poverty affect learners' available resources. Class attendance has been reported as a factor that is associated with learner performance. Learners who miss classes are more likely to perform poorly (Schmidt, 1983). The other factor that has effect on performance is learning preference, which refers to a person's "natural, habitat and preferred way" of assimilating new information (Reid, 1995). The positive effect of learning preferences is observed when there is a good match between learners' learning preference and educator's teaching approach (Mlambo, 2011).Therefore, the importance of analysing factors that influence learners' academic performances is their effect on academic motivation and their use for improving academic success (Ghazvini \& Khajehpour, 2011).

\section{Literature Review}

Disparities between male and female learners in academic performances, especially reading and mathematics achievement, have been a concern among educators for several decades (Letsoalo, Maoto, Masha, \& Lesaoana, 2016).For example, Ghazvini and Khajehpour(2011) reported that female learners have shown internal locus 
of control, using attitude, motivation, time management, anxiety, and self-testing strategies more extensively, and getting better marks in Literature. With male learners using concentration, information processing and selecting main ideas strategies more, and getting better marks in mathematics. Asante (2010) reported that high school males outperformed females in mathematics. In their investigation of whether higher school achievement by female learners in comparison to male learners can be explained by self-regulation; Weis, Heikamp and Trommsdorff (2013) showed that female learners outperformed their male counterparts in German achievement and behaviour regulation. Generally, males tend to do better at certain spatial and visual tasks while females tend to excel verbally (Dee, 2005; Guiso, Monte, Sapienza, \& Zingales, 2008).

Studies on the effect of gender of educator on learners' performances have reported mixed findings. Dee (2007) and Warwick and Jatoi (1994)found for US data that female teachers performed worse in mathematics and significant negative effects of female teachers on Grades 4 and 5 students' mathematics achievements for Pakistan were observed, respectively. Francis (2007)reported that educators' gender has significant effect on achievement mean scores of learners in science; male educators were more effective than their female counterparts. There are studies that provided evidence that female educators outperformed their male counterparts; of course under different conditions, e.g. Neugebauer, Helbig and Landmann (2011) and Spilt, Koomen and Jak (2012). However, Hogue, Razak, Mosa and Islam (2010), in their study of the effect of gender of educator on learner performance, found no (strong) evidence to claim whether students have to be taught by teachers of same or alternative gender. Also, Kolawole and Popoola (2011) in their study maintained that academic achievement is free of gender influence. The effect of educator-gender is significant on male learners or female learners, but conditionally. Therefore, differences between male and female learners in academic performances remain an important factor for education authorities, researchers and practitioners (Letsoalo et al., 2016).Learners' academic performance and achievement occupies a very important place in education as well as in the learning process; and learners' academic gain and learning performance is affected by various factors. Some are inherent such as mental and physical abilities, while others are outside-the-learner such as family social economic status, residential area of students, medium of instructions in schools and daily study hour.

According to Rogers (1997) as quoted byFaize and Dahar (2011), at the school level, socioeconomic status (SES) is by far the single most important factor accounting for the variance in student performance. Socioeconomic status, commonly conceptualised as the social standing or class of an individual or group, is an economic and sociological combined total measure of a person's work experience and of an individual's or family's economic and social position relative to others, based on income, education, and occupation (Saifi \& Mehmood , 2011; Letsoalo, Maoto, Masha, \& Lesaoana, 2017). Educational research practitioners, especially in South Africa, use wealth or SES measures as surrogates for well-being. Families with high SES often have more resources to utilise for preparing and supporting their children for formal education. The spin-off is evidenced by better performance of their children at school. Arguably, SES is an important factor for academic performance (Sui-Chu \& Willms, 1996). Having inadequate resources and limited access to available resources can negatively affect families' decisions regarding their children's development and learning. As a result, learners from low SES families are more likely to underperform at school, and are at greater risk of dropping out of schooling system. Rowen, Cohen and Raudenbush (2004) found that in the United States, the gaps in learner achievement among poor and advantaged learners are substantial. For example, Sum and Fogg (1991) found that learners from lower SES are ranked in the 19th percentile on assessments while learners from a mid to upper SES are ranked in the 66th percentile on assessments. Whilst SES measures give insight into some aspects of lifestyle, they fall short in truly understanding how people live - the realm of the broader concept of "well-being" of which wealth is just a part (Higgs, 2007). Socioeconomic status is not without controversy as it remains a latent construct. The fact that SES is assessed by a variety of different combinations of covariates has created an ambiguity in interpreting research findings (Sirin, 2005).

In addition to the effect of SES, studies revealed that parental involvement in school related activities has significant effect on their children's performances. That is, parental involvement is a significant variable that positively influences learners' education (Khajehpour \& Ghazvini, 2011). In other words, one important factor in socioeconomic background is the parental education. As highlighted by Fan and Chen (2001), parental involvement has been operationally defined as parental aspirations for their children's academic achievement and parents' conveyance of such aspirations to their children, as parents' communication with children about 
school, as parents' participation in school activities, as parents' communication with teachers about their children, and as the rules parents impose at home which are considered to be school-related. This somewhat chaotic state in the definition of the main construct not only makes it difficult to draw any general conclusion across the studies, but also may have contributed to the inconsistent findings in this area. The researcher acknowledges that parental involvement in school-related activities vary according to three conceptual approaches, as used by researchers to explain parental involvement along social-class lines: the culture of poverty, the institutional approach, and the cultural-capital approach(Lareau, 1987; Sui-Chu \& Willms, 1996). This paper does not intend to explicitly dwell into these conceptual approaches. Parents' education attainment has an effect on learners' performances. In other words, there is a profound impact of parent's education on their children's performance (Armstrong, Henson, \& Tom, 1981).

Among others, Rauf (1984) indicated that learners having educated parents are more likely to get good grades in their examinations than students having uneducated parents. Similar findings were found by Houtenville and Conway (2007) when they concluded that learners' achievements are positively related to parents' education and family income, and negatively related to the number of siblings. However, they did not establish how much was the relationship between students' performance and the level of mother's education as was done by Peters and Mullis in 1997. To be precise, Peters and Mullis (1997) found that parental education level had a significant effect on academic achievement of their children. They further quantified the effect of mothers' education to be $20 \%$ higher than the fathers' education level on the outcome of adolescents. The performance of science students is affected by the education level of their mother. Faize and Dahar (2011) concluded that science students having illiterate mothers performed significantly lower than students having educated mothers; and as the level of mothers' education increased, the performance of students also improved.

Research on educational production functions attempts to model the relation between resource inputs and school outcomes such as educational achievements or academic performances (Hedges, Laine, \& Greenwald, 1994). Many studies have been conducted on the effect of school resources on learner achievement, but the question is far from settled (Hakkinen, Kirjavainen, \& Uusitalo, 2003). South African schools are categorised into five groups, called quintiles, largely for purposes of allocation of financial resources. The poorest schools are in quintile 1 while the well-resources schools are in quintile 5. Schools in quintile 1, 2 and 3 have been declared no-fee schools, while schools in quintiles 4 and 5 are fee-paying schools. The idea of free schooling is primarily about removing the financial barriers to education. The quintile category of a school is a variable that is under the control of policy makers to alleviate the poverty status in schools, and therefore is a proxy for SES or community characteristics. The policy context of this variable is viewed as the amount of money given to schools per learner, provision of nutrition programmes and no-payment of fees by parents. School resources are usually measured at different levels(Hanushek, 1997), which include a) the real resources of the classroom (teacher education, educator experience and educator-learner ratios), b) financial aggregates of resources (expenditure per learner and educator salary), and c) measure of other resources in schools (specific educator attributes, administrative inputs, and facilities). Although school resources is often simplistically considered as a single construct, in reality, this construct be conceptualised as being multifaceted in nature.

In this paper, the researcher treats all these levels under one variable called school quintile. A basic problem in analysing the effect of school resources on learner achievement is that resources are likely to be correlated with unobserved characteristics that affect achievement. This lead to the studies giving inconclusive evidence that more resources allocated to schools would improve teaching and student learning, then eventually learners' performances (Hakkinenet al., 2003). For example, Hakkinen et al. (2003) found that school resources had no significant effects on any of the exam results. On the other hand, van der Berg (2007) showed that Grade 12 pass rates of schools were associated with, among others, teaching resources. Grade 12 is a final and $12^{\text {th }}$ year of basic education band in South Africa - a Grade or state before a learner can enrol for post-school qualification in institutions of higher learning such as university and (technical and vocational education and training) college. Also, Pan, Rudo and Smith-Hansen (2003) reported that results from analysis of fiscal and staffing data showed that high performing districts spent more money and employed more staff in certain instructional categories when compared to low-performing districts. This is the same assertion held by Considine and Zappala (2002)that schools in quintiles 4 and 5 (specifically, private schools) are more 
likely to have greater number of learners from high SES families, select learners with stronger academic abilities and have greater financial resources. However, Hedges et al. (1994) in their meta-analysis study caution that the statistical results of such studies depend entirely on the statistical approach used, and the power of statistical techniques adopted. In other words, the reliability of the all scientific studies lies in the methods used for data analyses. While the idea that providing more resources to schools would improve the performance of their learners has considerable popular appeal, it is not always supported by the evidence. In other words, policy makers believed that the provision of more resources to teaching and learning processes would directly improve learners' outcomes. Unfortunately, resources may be necessary but they are not entirely sufficient; for resources themselves are not self-enacting. The effect of resources depends entirely on how they are used. Therefore, resources matter only conditionally.

Theoretical Framework: The following theories were used to form the basis for this study:

The theory of human motivation: The theory of human motivation, also known as the Maslow's hierarchy of needs (Maslow, 1943), emphasises the need for human motivation in order to bring out the best possible potentials in human efforts. According to this theory, human is constantly preoccupied with need that must be met at a point in time and which in response gives birth to another need which are mostly insatiable in the long run. This theory, which derives its motivation form the Maslow theory of motivation, postulates that the satisfaction of a stage of need automatically gives rise to the next level of need (Maslow, 1943). In other words, humans are fuelled by a desire to achieve goals. Attaining goals helps humans satisfy specific needs and desires. Needs are categorised into a hierarchy, in which certain needs must be met before others (Maslow, 1943). Lower needs must be satisfied before higher-order needs can be reached. When learners are concerned about certain needs, their behaviour is centred on meeting those needs. Other concerns will then take precedence over learning and achievement. Therefore, if there is a deficiency in the needs or any are neglected it can result in hindering a learner's performance and behaviour in school. This theory guides in the understanding why learners behave the way that they do and it assists in determining how learning may be affected by some factors such as physiological or safety deficiencies. Therefore, this study was underpinned by theory of human motivation. Figure 1 is a schematic representation of Maslow's hierarchy of needs model.

\section{Figure 1: Maslow's hierarchy of needs}

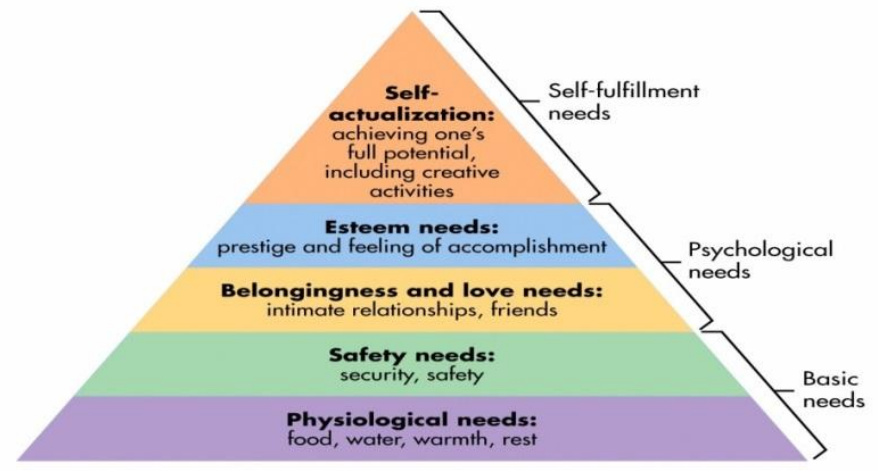

The system's theory input-output model: The system's theory input-output model advanced by LudwigVon Bertalanffy in the early 1950s; which postulates that an organised enterprise does not exist in vacuum or in isolation, is dependent on its environment in which it is established (Koontz \& Weihrich, 1988). They added that the inputs from the environment are received by the organisation which then transforms them into output after processing such inputs. Figure 2 makes this explanation more explicit. As adapted by this study, the learners (input) are admitted into the school with different inherent attributes, family and educational background; when they get into the school system, the school through its resources (both human and capital) process such learners through the learning process which is aided or made easier through the resources or variables attributed to such school. The effectiveness of such variables is measured through the output of the learners which is measured in term of their academic performances. All the component of the model (system) must function in harmony in order to achieve the envisaged outcome. Therefore, the inter relationship among 
the parts of a system have to be understood by all parties to ensure their inter-dependent nature of the parts(Oso \& Onen, 2005).

Figure 2: Input-Output model in education

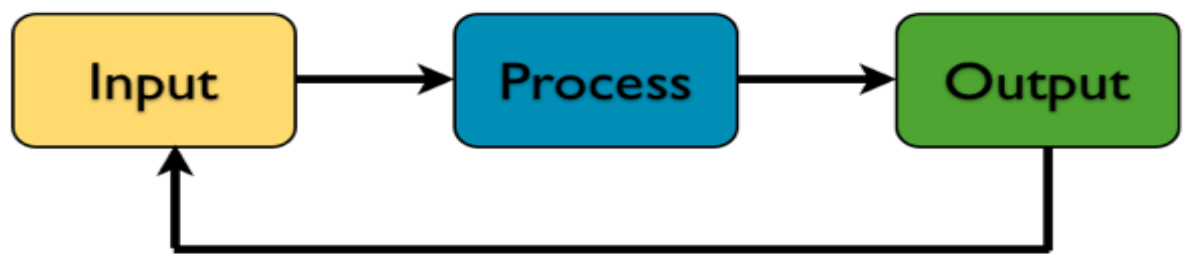

Feedback

Bray and Thomas Cube: Bray and Thomas (1995)advocate for multilevel approach, and criticise studies that consider univariate and bivariate data analyses only; and they consider multilevel approaches to be more comprehensive and that the approach allows for integration of insights gleaned from single-level approaches (Letsoalo, Maoto, Masha, \& Lesaoana, 2017). Bray and Thomas represented the multilevel approach by the Bray-Thomas Cube, as given by Figure 3 .

Figure 3: A Framework for comparative education analyses

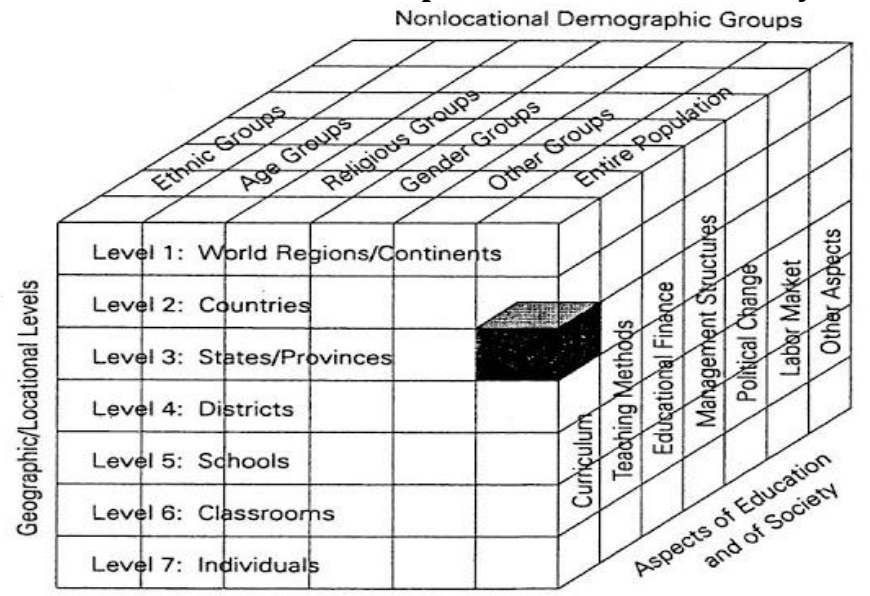

The vertical dimension of the cube comprises geographical levels (world regions, country, states/provinces, districts, school, classroom, and individual), the first horizontal dimension comprises seven aspects of education and society (curriculum, teaching methods, education finance, management structures, political change, labour markets and other aspects), and the second horizontal dimension comprises seven nonlocational demographic groups (ethical groups, age groups, regional groups, gender groups, other groups and the whole population). Whilst this study does not fully exploit the different aspects of the Bray-Thomas Cube, it is within this framework that the researcher pursued this comparative study.

Purpose of the Study: The purpose of this study was to investigate the influence of school variable on male and female academic performances. Specifically, the study sought to determine the extent to which school quintile influenced academic performances of learners in Gauteng Province. This study was aimed at comparing the overall performances of Grade 12 learners in Gauteng province. To achieve the mentioned objective, the null hypothesis that male and female Grade 12 learners did not perform significantly differently was tested at $\alpha=0.05$ (2-sided). The guiding question was: Do male and female Grade 12 learners have differing chances of passing Grade 12, even after adjusting for school quintile? Therefore, the researcher intended to draw inference at the gender-level, the unit of analysis. This is the first study to be conducted that compares the overall performances of Grade 12 learners in Gauteng Province, wherein the study end-point is 
binary or dichotomous (pass or not pass), using disaggregated approach, hierarchical model or multilevel modelling.

\section{Methodology}

This cross-section quantitative study(Creswell, 2003), which followed an ex-post-facto design(Cohen, Manion, \& Morison, 2000), used secondary data called Grade 12 dataset as supplied by the Department of Basic Education through Umalusi, the Council for Quality Assurance (CQA) in General and Further Education and Training (FET) in South Africa. Umalusi council is responsible for quality assuring Senior Certificate (SC) and National Senior Certificate (NSC), amongst other responsibilities. The Grade 12 dataset contains correlated and clustered data. Such data requires statistical techniques such as disaggregated analysis or multilevel models that account for clustering. Multilevel models are a more advanced form of simple and multiple linear regression models (Letsoalo et al., 2016). The classical regression models, adopted for investigate the relationships between one or more independent variables and a dependent one, are based on the hypothesis of non-correlation between observations. The analysis of the individuals as non-correlated leads to distortions: underestimation of standard error of the model or the attribution of non-existing statistical effects between variables (Ivanović \& Baldigara, 2006; Letsoalo \& Lesaoana, 2010).

Data were received in excel format and comprised of pseudo-learner identifiers, learning area (school subjects) per learner, final outcome, final score (\%), province (Gauteng Province), learner gender (male or female), school quintile and examination centre (school identifier). Data management was accomplished by the use of the combination of software packages Excel and Stata (StataCorp, 2015). The variables of interest were transferred directly into the Stata V14 (StataCorp, 2015)environment wherein statistical analysis was performed. Summary statistics for all categorical variables were presented as frequencies and proportions (expressed as percentages). The study end-point was whether or not a learner passed Grade 12 (pass or not pass). Therefore, the outcome variable was binary. Disaggregated data analysis for binary end-point, also called multilevel modelling for dichotomous outcome or hierarchical logistic regression modelling, as advocated by Letsoalo and Lesaoana(2012), was used to compare the overall performances of male and female learners, and to determine the effect of school quintile on the overall performances between male and female learners. The interpretation of the results was performed at $95 \%$ confidence limit or 0.05 error rate.

\section{Results and Interpretation}

The results are presented in tabular formats and are given at two levels, descriptive analysis and inferential statistics. All summary statistics are given as frequencies and proportions (expressed in percentages) since all variables are categorical. Pearson chi-square test was used to test for association between binary endpoint, which indicates whether or not a learner passed or did not pass Grade 12 and gender, which indicates whether or not a learner was a male or female learner. Disaggregated analysis or hierarchical logistic regression models, both crude (null) and adjusted models, were used to determine the likelihood of observing the result "pass" between male and female learners. The parameter of interest was odds ratio (OR), which is used to compare the relative odds of the occurrence of the outcome of interest, given exposure to the variable of interest (Szumilas, 2010). Possible interpretation of OR is presented by Table 1 (Szumilas, 2010):

Table 1: Interpretations of odds ratios

\begin{tabular}{ll}
\hline Odds Ratio (OR) & Interpretation \\
\hline Less than $1(\mathrm{OR}<1)$ & Exposure associated with lower odds of outcome \\
Equals $1(\mathrm{OR}=1)$ & Exposure does not affect odds of outcome \\
Greater than $1(\mathrm{OR}>1)$ & Exposure associated with higher odds of outcome \\
\hline
\end{tabular}

Descriptive statistics: The participants in the study consisted of 98894 Grade 12 learners, (44940 [45.44\%] males and 53954 [54.56\%] females) who sat for Grade 12 examination in 2008 academic year in Gauteng Province. Therefore, females were marginally more than male learners. Table 2 presents within gender distribution of results, and indicates that the proportion of females learners were marginally higher than 
those of male learners only in the category of Bachelor. Otherwise, the proportions of males were marginally higher in all other categories of results. Specifically, the proportion of male learners who failed Grade 12 examinations in 2008 academic year was marginally higher than that of female learners $26.03 \%$ versus 25.36\%). The categories of Bachelor, Diploma, Higher certificate and National senior certificates indicated that a learner had passed Grade 12.

Table 2: The within-gender distribution of results

\begin{tabular}{llrlr}
\hline \multirow{2}{*}{ Results } & \multicolumn{3}{c}{ Male Learners } & \multicolumn{2}{c}{ Female Learners } \\
& Count & Percent & Count & Percent \\
\hline Bachelor & 12427 & 27.65 & 16708 & 30.97 \\
Diploma & 12953 & 28.82 & 14270 & 26.45 \\
Higher Certificate & 7834 & 17.43 & 9284 & 17.21 \\
National Senior Certificate & 29 & 0.06 & 8 & 0.01 \\
Failed & 11697 & 26.03 & 13684 & 25.36 \\
Total & 44940 & 100.00 & 53954 & 100.00 \\
\hline
\end{tabular}

Table 3 presents this information in terms of whether or not a learner had passed Grade 12. The proportion of female learners who passed Grade 12 was marginally higher than that of male learners. Also, the frequency of female learners who passed Grade 12 was marginally higher than that of male learners. Although the frequency of female learners who did not pass Grade 12 was marginally higher than that of males; the proportion of those who did not pass favoured females; for $25.36 \%$ female learners did not pass Grade 12 as compared to $26.03 \%$ of their male counterparts.

Table 3: Distribution of learner gender according to whether or not a learner has passed

\begin{tabular}{lrrrr}
\hline \multirow{2}{*}{ Binary End-Point } & \multicolumn{2}{c}{ Male Learners } & \multicolumn{2}{c}{ Female Learners } \\
& Count & Percent & Count & Percent \\
\hline Not Passed & 11697 & 26.03 & 13684 & 25.36 \\
Passed & 33243 & 73.97 & 40270 & 74.64 \\
Total & 44940 & 100.00 & 53954 & 100.00 \\
\hline
\end{tabular}

Inferential Statistics (Disaggregated Analysis): Table 4 indicates that learners who passed Grade 12 were marginally more than those who did not pass $[n=73512(74.33 \%)$ versus $n=25381(25.63 \%)]$. As presented by Table 4, of all learners who did pass Grade 12 in 2008 academic year; 40269 (54.78\%)and 33243 (45.22\%) were female and male learners, respectively. Likewise, of all learners who did not pass; 13684 (53.91\%)and 11697 (46.09\%) were female and male learners, respectively. The proportion of female learners who passed was higher than the proportion of male learners.

Table 4: Test for association between gender of a learner and binary end-point

\begin{tabular}{lllllll}
\hline \multirow{2}{*}{ Binary End-Point } & \multicolumn{3}{c}{ Male Learners } & \multicolumn{2}{c}{ Female Learners } & \multicolumn{2}{c}{ Total } \\
& Frequency & Percent & Frequency & Percent & Frequency & Percent \\
\hline Not Passed & 11697 & 46.09 & 13684 & 53.91 & 25381 & 100.00 \\
Passed & 33243 & 45.22 & 40269 & 54.78 & 73512 & 100.00 \\
Total & $\mathbf{4 4 9 4 0}$ & $\mathbf{4 5 . 4 4}$ & $\mathbf{5 3 9 5 3}$ & $\mathbf{5 4 . 5 6}$ & $\mathbf{9 8 8 9 3}$ & $\mathbf{1 0 0 . 0 0}$ \\
& \multicolumn{7}{c}{ Pearson $\chi_{(1)}^{2}=5.6870$} & $P r=0.017$ & & \\
\hline
\end{tabular}

A chi-square test for association, as shown in Table 4, was performed to examine the relation between gender of a learner and binary end-point (passed or not passed). The association between these variables was 
significant, $\chi_{(1)}^{2}=5.687, \mathrm{p}=0.017$. Male learners than female learners were less likely to pass Grade 12 . In other words, there was sufficient evidence that the proportion of male learners to the proportion of female learners in the levels of binary end-point was significantly different. Therefore, Male learners and female learners performed significantly differently in 2008 academic year.

The unadjusted model or crude estimates, as depicted by Table 5, indicated that female learners were significantly 1.035 more likely to pass Grade 12 than their male counterparts ( $p=0.016, \mathrm{OR}=1.035,95 \% \mathrm{CI}$ : 1.006 - 1.065). The odds of passing Grade 12 increased significantly by factor of about 1.035 for female learners over that of male learners. This implies that hypothesis that the odds of passing Grade 12 between male and female learners are the same cannot be accepted. Therefore, there is sufficient evidence that female learners were significantly more likely than male learners to pass Grade 12 in 2008 academic year.

Table 5: Crude estimates

\begin{tabular}{lcccc}
\hline Covariate & OR & Std. Err. & $\mathbf{P}>|\mathbf{z}|$ & $\mathbf{9 5 \%}$ Confidence Interval \\
\hline $\begin{array}{l}\text { Gender } \\
\text { Male }\end{array}$ & & & \\
Female & 1.035 & 0.015 & 0.016 & $(1.006000-1.065000)$ \\
Constant & 2.843 & 0.304 & $<0.001$ & $(2.784000-2.903000)$ \\
& & Baseline category & \\
\hline
\end{tabular}

Table 6 indicates that school quintile is a significant predictor of the binary outcome, pass or not pass (p < 0.0001). The result from adjusted model indicates that female learners were significantly 1.04 more likely to pass Grade 12 than male learners ( $p=0.01, \mathrm{OR}=1.04,95 \%$ CI: $1.0095-1.0716)$. There is sufficient evidence that, after controlling for school quintile, female learners than male learners were significantly more likely to pass Grade 12.

Table 6: Model estimates after adjusting for school quintile

\begin{tabular}{|c|c|c|c|c|c|}
\hline Covariate & & OR & Std. Err. & $\mathbf{P}>|\mathbf{z}|$ & 95\% Confidence Interval \\
\hline \multicolumn{6}{|l|}{ Gender } \\
\hline & \multicolumn{5}{|l|}{ Male } \\
\hline & Female & 1.040 & 0.016 & 0.01 & $(1.009512-1.071560)$ \\
\hline \multicolumn{6}{|c|}{ School Quintile } \\
\hline & \multicolumn{5}{|l|}{$1^{\mathrm{b}}$} \\
\hline & 2 & 0.859 & 0.031 & 0.028 & $(0.801086-0.921010)$ \\
\hline & 3 & 1.072 & 0.340 & $<0.001$ & $(1.007340-1.140600)$ \\
\hline & 4 & 1.437 & 0.453 & $<0.001$ & $(1.351104-1.528653)$ \\
\hline & 5 & 5.858 & 0.197 & $<0.001$ & $(5.485779-6.254520)$ \\
\hline \multirow{2}{*}{\multicolumn{2}{|c|}{ Constant }} & 1.553 & 0.046 & $<0.001$ & $(1.465532-1.645980)$ \\
\hline & & \multicolumn{4}{|c|}{ bBaseline category } \\
\hline
\end{tabular}

Therefore, if school quintile was constant (i.e. if all schools were resourced equally) then female learners would have been expected to have significantly better chances of passing Grade 12. The chance of passing Grade 12 was 1.04 more likely for female learners than that of male learners after controlling for school quintile. 


\section{Conclusion}

The findings in this paper indicate that female learners than male learners had better chances of passing Grade 12 in Gauteng Province. Both adjusted and unadjusted hierarchical models indicate that female learners were significantly more likely to pass Grade 12 . Hierarchical models are more powerful as they are able to account for correlation between clustered or correlated observations, and are able to adjust for individual covariates so as to quantify the effect of each covariate. Therefore, they give reliable estimates (Letsoalo \& Lesaoana, 2010).The researcher believes that this study represents a significant contribution on the question of whether or not school resources and learners' achievement are related. The general conclusion of the disaggregated analysis presented in this article is that school quintiles are systematically related to learner achievement and that these relations are large enough to be educationally important. In addition, authorities will appreciate that as they allocate resources to the schools - the issue of learner-gender is taken into consideration. While the findings of this research should provide a clear direction for policymakers - that resources are positively related to learners' achievements - the practitioners should be aware that the impact of the resources lies in how the resources are used in line with advocated policies. Therefore, the relationship between school resources and learner achievement has been controversial, in large part because it calls into question a variety of traditional policy approaches. The findings in this study are limited to the performances of learners in Gauteng Province. Any inference or extrapolation of results has to be plausible in situations and setup similar to Gauteng Province. Further, it is recommended that similar studies be conducted for all other years, all other provinces and that all other covariates which were found to be significantly associated with learners' performances, as determined by other studies, be included, controlled for or adjusted for in the analyses.

Challenges: The Grade 12 dataset did not contain all predictor variables such as parents' attributes, family attributes, educators' attributes, learners' backgrounds and learners' ages. It has been shown from other studies that these factors (or covariates) important predictors of learners' performances. It would have been very useful to test if these covariates would yield similar results in the South African setting, especially in Gauteng Province. Therefore, Umalusi council is encouraged to collect all possible covariates for further studies and analyses.

\section{Acknowledgement}

a) The author declares that he has no financial or personal relationship(s) that may have inappropriately influenced him in writing this article.

b) The author would love to express his sincere gratitude to Eunice Mtshali and Given Luvhimbi (Information Librarians: Tshwane University of Technology), and Alice Machele (Client Manager Services: Tshwane University of Technology) for technical assistance. Special appreciation goes to Umalusi Council for allowing the author to use the Grade 12 dataset, and Lerato Masemola (Manager: SIR Unit, Umalusi Council) for data management.

\section{References}

Adeyemi, T. (2008). Predicting students' performance in senior secondary certificate examinations from performance in junior secondary certificate examinations in Ondo State, Nigeria. Middle-East Jpurnal of Scientific Research, 3(2), 144 - 161.

Armstrong, D., Henson, K. T.\& Tom, V. S. (1981). Education: An Introduction. Macmillan Publishing, Inc.

Asante, 0. A. (2010). Sex differences in mathematics performance among senior high students in Ghana. Gender \& Behaviour, 3279 - 3289.

Bray, M.\& Thomas, R. M. (1995). Levels of comparison in educational studies: Different insights from different literatures and the value of multilevel analyses. Harvard Educational Review, 65(3), 472 - 491.

Cohen, L., Manion, L.\& Morison, K. (2000). Research methods in education. London: Routledge Falmer.

Considine, G.\& Zappala, G. (2002). Factors influencing the educational performance of students from disadvantaged backgrounds. In T. Eardley, \& B. Bradbury, Competing visions: Refereed proceedings of the National Social Policy Conference 2001 (pp. 91 - 107). Sydney: Social Policy Research Cetre, University of New South Wales. 
Creswell, J. (2003). Research design:Qualitative, quantitative and mixed methods approaches (2nd ed.). Thousand Oaks: SAGE.

Dee, T. S. (2005). Teachers and gender gaps in student achievement: Working paper \#11660. Retrieved August 29, 2017, from http://www.nber.org/papers/w11660

Dee, T. S. (2007). Teacher and the gender gap in student achievement. Journal of Human Resources, 42(3), 528 $-554$.

Faize, F. A.\& Dahar, M. A. (2011). Effect of mother's level of education on secondary grade science students in Pakistan. Research Journal of Internatıonal Studies, (9), 13919.

Fan, X.\& Chen, M. (2001). Parental involvement and students' academic achievement: A meta-analysis. Educational Psychology Review, 13(1), 1 - 22.

Francis, A. A. (2007). Student and teacher related variables as determinants of secondary school students academic achievement in chemistry. Journal of Pendidikan, 32, 3 - 18.

Ghazvini, S. D.\& Khajehpour, M. (2011). Gender differences in factors affecting academic performance of high school students. Procedia Social and Behavioral Sciences, 15, 1040 - 1045.

Guiso, L., Monte, F., Sapienza, P.\& Zingales, L. (2008). Culture, gender and math. Science, 320(5880), 1164 1165.

Hakkinen, I., Kirjavainen, T.\& Uusitalo, R. (2003). School resources and student achievement revisited: new evidence from panel data. Economics of Education Review, 22, 329-335.

Hanushek, E. A. (1997). Assessing the effect of school resources on students performance: An update. Educational Evaluation and Policy Analysis, 19(2), 141 - 164.

Hedges, L. V., Laine, R. D.\& Greenwald, R. (1994). Does money matter? A meta-analysis of studies of the effects of differential school inputs on student outcomes. Educational Researcher, 23(3), 5 - 14.

Higgs, N. T. (2007). Measuring and understanding the well-being of Soth Africans: Everyday quality of life in South Africans. Social Indicators Research, 81, 331 - 356.

Hoque, K., Razak, A., Mosa, F.\& Islam, R. (2010). Impact of teacher gender on primary students' achievement: A study at Malaysian standpoint. Journal of Sociological Research, 4(1), 124 - 144.

Houtenville, A. J.\& Conway, K. S. (2007). Parental effort, school resources and student achievement . American Economic Association Meetings.

Ivanović, Z.\& Baldigara, T. (2006). Multilevel models in education process performance evaluation. Tourism and Hospitality Management, 12(2), 25 - 36.

Khajehpour, M.\& Ghazvini, S. D. (2011). The role of parental involvement affect in children's academic performance. Procedia-Social and Behavioral Sciences, 15, 1204-1208. Procedia-Social and Behavioral Sciences, 15, 1204 - 1208.

Kolawole, E. B. \& Popoola, A. A. (2011). Four Ability Process Dimension (4APD) as a as a function of improving teaching and learning of Basic Mathematics in Ekiti State Secondary schools. ABACUS. Journal of Mathematics Association of Nigeria, 36(1), 113 - 118.

Koontz, H.\& Weihrich, H. (1988). Management. New York: McGraw-Hill, INC.

Kyei, K. A.\& Maboko, T. (2016). Performance of high school students in Vhembe district. Journal of Economics and Behavioral Studies, 8(1), 50 - 58.

Lacour, M.\& Tissington, L. D. (2011). The effect of poverty on academic achievement. Educational Research and Reviews, 6(7), 522 - 527.

Lareau, A. (1987). Social class differences in family-school relationships: The importance of cultural capital. Sociology of Education, 60, 73 - 85.

Letsoalo, M. E.\& Lesaoana, M. (2010). Analysis of clustered measurements: A comparison of the comparison of the performance of foundation year students, 1994 cohort with those of direct students, 1995 cohort, at the University of Limpopo, South Africa. In C. Reading (Ed.), Proceedings of the eighth international conference on teaching statistics. ICOTS.

Letsoalo, M. E.\& Lesaoana, M. A. (2012). Determination of causal effect in observational studies: Analysis of correlated data with binary end-points. Journal of Mathematics and System Sciences, 2, 119 - 125.

Letsoalo, M. E., Maoto, R. S., Masha, J. K.\& Lesaoana, M. (2017). The effect of gender on learner achievement in Gauteng and the Western Cape Provinces of South Africa. Gender \& Behaviour, 15(2), 9177 -9184.

Letsoalo, M. E., Maoto, R. S., Masha, J. K.\& Lesaoana, M. A. (2016). Gender as a unit of analysis: performance of male and female learners in Gauteng and Western Cape Provinces of South Africa. Gender and Behaviour, 14(2), 7504 - 7512.

Maslow, A. H. (1943). A theory of human motivation. Psychological Review, 50, 370 - 396. 
Mlambo, V. (2011). An analysis of some factors affecting student academic performance in an introductory biochemistry course at the University of West Indies. Caribbean Teaching Scholar, 1(2), 79 - 92.

Neugebauer, M., Helbig, M.\& Landmann, A. (2011). Unmasking the myth of the same-sex teacher advantage. European Sociological Review, 27(5), 669 - 89.

Oso, W. Y.\& Onen, D. (2005). A general guide to writing research proposal and reports: A book for beginning researchers (2nd ed.). Kampala, Uganda: Makerere University Press.

Pan, D., Rudo, Z.\& Smith-Hansen, L. (2003). Resource allocation does Matter in improving student performance. Conference of the American Education Finance Association. Orlando.

Peters, H. E.\& Mullis, N. C. (1997). The role of family income and sources of income in adolescent achievement. In G. Duncan, \& J. Brooks-Gunn, Consequences of growing up poor (pp. 340 - 381). Russell Sage Foundation Press.

Rauf, A. (1984).Dynamic Educational Psychology. Lahore: Pakistan: Caravan Book House.

Reid, J. M. (1995). Learning styles in the ESL/EFL classroom. Boston: Heinle \& Heile Publishers.

Rich, A. (2000). Beyond the classroom: How parents influence their children's education. CIS Policy Monograph 48, Centre for Independent Studies, Sydney.

Rogers, W. T. (1997). Socio-economic status strong predictor of performance. Alberta Teachers' Association Publication, 32(3).

Rowan, B., Cohen, D. K.\& Raudenbush, S. W. (2004). Improving the educational outcomes of students in poverty through multidisciplinary researcg and development. Retrieved August 25, 2017, from http://www.isr.umich.edu/carss/about/Prospectus.pdf

Saifi , S.\& Mehmood , T. (2011). Effect of socioeconomic status on student achievement. International Journal of Social Sciences and Education, 1(2), 119 - 128.

Schmidt, R. (1983). Who maximizes what? A study in student time allocation. American Economic Review, 73(2), 23 - 28.

Sirin, S. R. (2005). Socioeconomic status and academic achievement: A meta-analytic review of research. Review of Educational Research, 75(3), 417 - 453.

Spilt, J. L., Koomen, H. M.\& Jak, S. (2012). Are boys better off with male and girls with female teachers? A multilevel investigation of measurement invariance and gender match in teacher-student relationship quality. Journal of School Psychology, 50(3), 363 - 378.

StataCorp. (2015). Stata statistical software (Version 14). College Station, TX: StataCorp LP.

Sui-Chu, E. H.\& Willms, J. D. (1996, April). Effects of parental involvement on eighth-grade achievement. Sociology of Education, 69(2), 126 - 141. doi: 168.172.0.247

Sum, A. M. \& Fogg, W. N. (1991). The adolescent poor and the transitionto early childhood. In P. Edelman, \& J. Ladner,Adolescence \& poverty: Challenge for the 1990s (pp. 37 - 110). Lanham, MD: Center for National Policy Press.

Szumilas, M. (2010). Explaining Odds Ratios. J Can Acad Child Adolesc Psychiatry, 19(3), 227 - 229.

van der Berg, S. (2007). Apartheid's enduring legacy: Inequalities in education. Journal of African Economies, 16(5), $849-880$.

Warwick, D. P.\& Jatoi, H. (1994). Teacher gender and student achievement in Pakistan. Comparative Education Review, 38(3), 377 -399.

Weis, M., Heikamp, T.\& Trommsdorff, G. (2013). Gender differences in school achievement: The role of selfregulation. Frontiers in Psychology, 4, 442. doi:10.3389/fpsyg.2013.00442. 